\title{
Writing with a purpose
}

\author{
Dhungana $\mathbf{V}$ \\ Assistant Editor, Kathmandu University Medical Journal (KUMJ)
}

\begin{abstract}
Acience has revolutionised everything in the past $\checkmark$ couple of centuries or even fifty years, including our thought and knowledge. Even today it is spreading its wings every moment, expanding the frontiers of knowledge.
\end{abstract}

Medical Science is not aloof from this revolution. The art and science of medicine has grown all along in many aspects. One of such commendable developments is the medical journal. Writing in scientific journals has been a traditional way of communication in the medical world for many years both in the West and the East. This still holds true today. And this communication always holds a purpose. Whatever we write, we all write with a purpose. We write to share, and embark on discussions and further research that ultimately leads to some productive outcome for good of the common people. Writing in a journal like Kathmandu University Medical Journal (KUMJ) perfectly serves such a purpose.

KUMJ is an indexed and internationally recognised standard medical journal. It stands tall among scientific publications in Nepal. KUMJ has attained such a position by publishing quality scientific papers and helping to serve the purpose of effective medical communication and discussions. Furthermore it aims to continue the journey with the same purpose and to attain greater heights. To maintain this, KUMJ has remained and will remain busy with new, creative ideas and efforts.

The recent years have seen more and more people taking interest in academics and researches for promoting and advocating good ethical practices. KUMJ has been a supporter of these trends. It has complied good ethical publication guidelines for healthy, creative and effective researches and articles.

Presently, some endeavour is in progress to setup an association of medical editors to increase the solidarity and effectiveness among practitioners of this art in Nepal. Though not officially launched yet, one can have great hopes from such collaboration. Here at KUMJ, we would like to declare our commitment towards quality researches, unusual case reports, significant audits, innovative articles on medical education, good book reviews, and better students' participation via student KUMJ.

Participation by authors from different areas of specialisation/ fields has always been encouraging, and we intend continuously to further increase our authorship and readership. Regarding various publication categories, we have recently added an "Audit" section with the intention of including audits of special significance, and/or rarer diseases.

We would like to encourage the authors to keep participating in our efforts and to keep writing. We would like to thank our reviewers for their selfless efforts through all these years to bring KUMJ to this height. We will definitely bring programmes/schemes to acknowledge their participation and to also help readers in all ways possible. We are in fact a team with the objective of a better KUMJ!

One bitter feeling is the trend of knowingly or unknowingly copying and pasting information from the Internet. This has led to few cases of plagiarism being reported recently. Even a single case of such an act is unpardonable in this profession. KUMJ has now a policy and process to make sure that it will be free from such plagiarism in the future. We intend to check all submitted articles thoroughly before publication.

Regarding our esteemed readers, who range from students to specialist, from local to international levels, we would like to thank all for their continued interest and support. We request you all to give constructive suggestions every now and then.

Our readers, the authors and we editors can work together at KUMJ and serve the purpose of effective scientific writing and communication for the good of the community. 